\title{
Verification of Controlled Grafting of Styrene from Cellulose via Radiation-Induced RAFT Polymerization
}

\author{
Murat Barsbay, ${ }^{\dagger}$ Olgun Giiven, ${ }^{*}, \dagger$ Martina H. Stenzel,, Thomas P. Davis, \\ Christopher Barner-Kowollik, ${ }^{*}$ and Leonie Barner*,"
}

Faculty of Science, Department of Chemistry, Hacettepe University, 06532 Beytepe, Ankara, Turkey, and Centre for Advanced Macromolecular Design, School of Chemical Sciences and Engineering, The University of New South Wales, Sydney, NSW 2052, Australia

Received April 7, 2007; Revised Manuscript Received July 20, 2007

\begin{abstract}
Reversible addition-fragmentation chain transfer (RAFT) polymerization was applied to radiationinduced graft polymerization of styrene from cellulose. The grafting of styrene from cellulose substrates using the chain transfer agent cumyl phenyldithioacetate was confirmed by Raman and X-ray photoelectron spectroscopy, differential scanning calorimetery, thermogravimetric analysis, scanning electron microscopy, and contact angle analysis. Grafted polystyrene chains were cleaved from the cellulose surface by acidic hydrolysis of the cellulose. The number-average molecular weight and polydispersity index of the grafted and the free (nongrafted) polystyrenes obtained under identical conditions were determined by size exclusion chromatography. Grafted and nongrafted polystyrenes have almost the same (near theoretical) molecular weight and narrow polydispersity, thus proving for the first time the control of the grafting process mediated via RAFT without any prior functionalization of the surface.
\end{abstract}

\section{Introduction}

Cellulose is the most common organic polymer and a very important sustainable raw material. ${ }^{1}$ Over the past decade, research to utilize cellulose as a base for the development of new polymers has intensified. ${ }^{2}$ Cellulose is a very attractive raw material due to properties like hydrophilicity, biocompatibility, stereoregularity, multichirality, reactive hydroxyl groups and the ability to form superstructures. ${ }^{2}$ Esters and ethers of cellulose are used in coatings, films, membranes, controlled-release systems, and pharmaceuticals. ${ }^{1,3}$ One of the well-established methods to modify cellulose is via grafting of polymer onto the surface of cellulose. ${ }^{4-8}$ Traditionally, free radical polymerization is used to graft vinyl polymers from cellulose, accepting the disadvantage that the molecular weight and molecular weight distribution of the grafts are not controlled. With the advent of controlled free radical polymerization techniques, such as nitroxide-mediated polymerization (NMP),${ }^{9-12}$ atom transfer radical polymerization (ATRP) $)^{13,14}$ and reversible addition-fragmentation chain transfer $(\mathrm{RAFT})^{15-19}$ polymerization, it is now possible to synthesize polymers with predetermined molecular weight and low polydispersity for a great variety of vinyl monomers. RAFT is of particular interest as a very wide range of (functional) monomers can be polymerized in a controlled manner under non-demanding reaction conditions (e.g., tolerance to oxygen and low temperatures) via this technique. Thiocarbonylthio compounds are used as chain transfer agents (CTA) during RAFT polymerization.

Recently, NMP, ${ }^{20}$ ATRP, ${ }^{21-24}$ and RAFT ${ }^{25-28}$ were used to modify cellulose via grafting of polymers from the surface. In all published reports to date, cellulose had to be functionalized

\footnotetext{
* To whom correspondence should be addressed. (L.B.) E-mail: leonie.barner@unsw.edu.au. Telephone: +61 (2) 9385 5745. Fax: +61 (2) 9385 6250. (O.G.) E-mail: guven@ @acettepe.edu.tr. Telephone: +90 (312) 297 7977. Fax: +90 (312) 2977977

Faculty of Science, Department of Chemistry, Hacettepe University.

$\doteqdot$ Centre for Advanced Macromolecular Design, School of Chemical Sciences and Engineering, The University of New South Wales.
}

prior to grafting; e.g., the surface was functionalized with an ATRP initiator or RAFT agent to utilize grafting. Recently, we reported the development of ambient temperature RAFT agents ${ }^{29,30}$ which open the possibility to perform RAFT polymerization at ambient temperature by means of $\gamma$-radiation. ${ }^{31-33}$ Subsequently, we reported that the RAFT technique in conjunction with $\gamma$-radiation can be applied to graft polymers from polypropylene (PP) surfaces in a controlled manner without prior functionalization of the surface. ${ }^{34-36}$ The RAFT agent cumyl phenyldithioacetate (CPDA) ${ }^{30}$ was employed to mediate the grafting of styrene ${ }^{34}$ and a mixture of styrene and $m$-isopropenyl$\alpha, \alpha^{\prime}$-dimethylbenzyl isocyanate ${ }^{35}$ from PP lanterns. In 2007, Hill and co-workers used the RAFT technique to graft tertbutyl acrylate from an ethylene-propylene copolymer via $\gamma$-radiation. ${ }^{37}$ Application of $\gamma$-radiation generates radicals on the polymeric surface and in the monomer solution. Monomer radicals and radicals formed on the surface initiate propagating chains, which subsequently add to the thiocarbonyl group of the RAFT agent. In the course of grafting, both grafted polymer (on the surface) and free, nongrafted polymer (in the solution) are generated. Because of the covalent binding of the polymeric chains to the PP surface, the grafted polymer cannot be easily characterized by conventional techniques, such as size exclusion chromatography (SEC). As grafted and free polymers are mediated by the same RAFT agent, the molecular weights and molecular weight distributions of the grafted polymer and the free polymer should be very similar. In our recent work, we therefore analyzed the free polymer instead of the grafted polymer and assumed that the resulting molecular weights and polydispersity of the free polymers were good indicators for the properties of the grafted polymers. In this work, we conclusively demonstrate that the molecular weight and polydispersity of the grafted polymer are almost identical to the molecular weight and polydispersity of the free polymer. Styrene was grafted from a substrate that can later be degraded completely without affecting the grafted polymer. Thus, cellulose was used as the substrate since it can be completely 


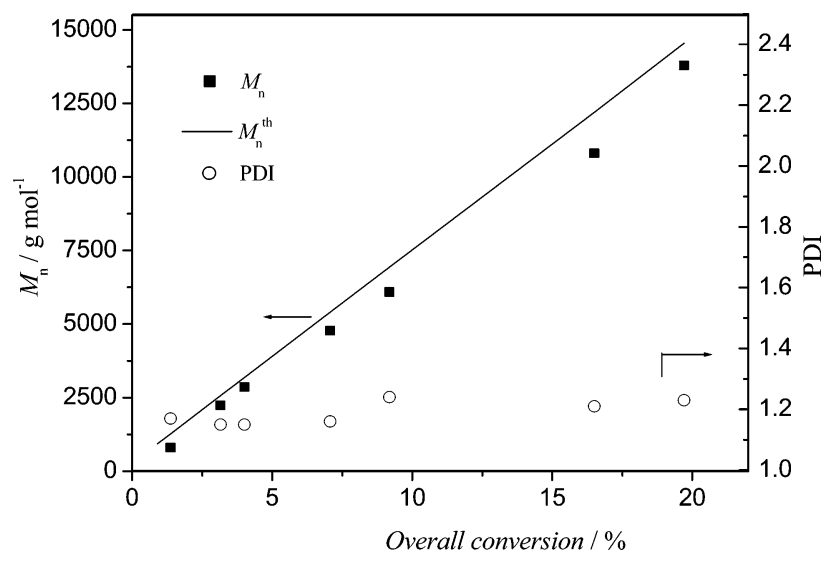

Figure 1. Evolution of number-average molecular weight, $M_{\mathrm{n}}$, and polydispersity index, PDI, vs the monomer conversion for free polystyrene formed during $\gamma$-initiated graft polymerization from cellulose mediated via the RAFT agent cumyl phenyldithioacetate (CPDA): $[\mathrm{St}]=3.45 \mathrm{~mol} \mathrm{~L}^{-1}$, cellulose $(0.04 \mathrm{~g})$, dose rate $0.09 \mathrm{kGy}$ $\mathrm{h}^{-1}$, in dioxane-water $(98: 2 \mathrm{v} / \mathrm{v}),[\mathrm{St}] /[\mathrm{CPDA}]=690: 1$, at room temperature.

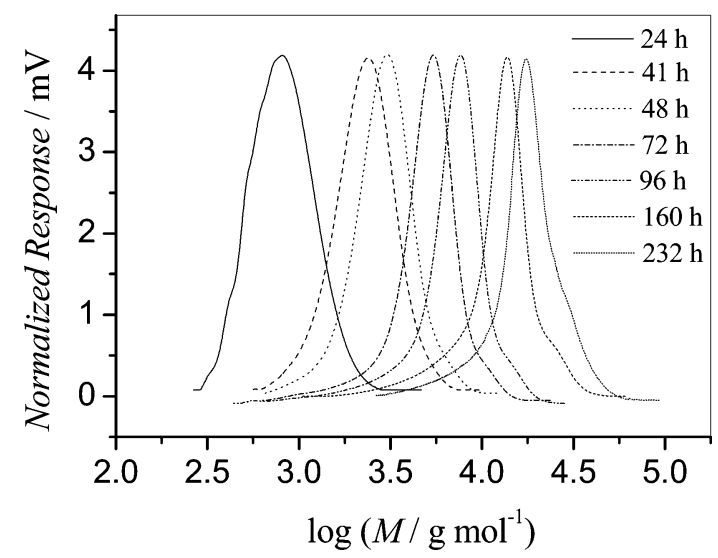

Figure 2. Evolution of molecular weight distribution vs time for free polystyrene formed during $\gamma$-initiated graft polymerization from cellulose mediated via the RAFT agent cumyl phenyldithioacetate (CPDA): $[\mathrm{St}]=3.45 \mathrm{~mol} \mathrm{~L}^{-1}$, cellulose $(0.04 \mathrm{~g})$, dose rate $0.09 \mathrm{kGy}$ $\mathrm{h}^{-1}$, in dioxane-water $(98: 2 \mathrm{v} / \mathrm{v}),[\mathrm{St}] /[\mathrm{CPDA}]=690: 1$, at room temperature.

Scheme 1. Cumyl Phenyl Dithioacetate

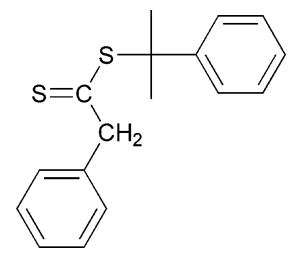

degraded by acid treatment without affecting the formed grafts. Subsequently, it was possible to fully characterize the grafted polymers including their molecular weight and polydispersity. Free polymers formed during the polymerization were analyzed as well, and the results were compared with results from the grafted polymers.

\section{Experimental Section}

Materials. Styrene (Aldrich, 99\%) was freed from inhibitor by percolation through a column of activated basic alumina. The CTA used in the polymerizations, cumyl phenyldithioacetate (CPDA), was prepared according to the procedure described elsewhere. ${ }^{38}$ Whatman No. 1 filter paper was used as cellulose substrate due to its high cellulose content ( $98 \% \alpha$-cellulose), lesser amount of impurities, and ease of chemical modification. ${ }^{22}$ Each cellulose
Table 1. Glass Transition Temperature for Polystyrene and Cellulose-g-polystyrene Copolymers

\begin{tabular}{|c|c|c|c|c|}
\hline sample & $\begin{array}{l}M_{\mathrm{n}}{ }^{a} / \mathrm{g} \\
\mathrm{mol}^{-1}\end{array}$ & $\begin{array}{l}\text { onset } \\
\text { temp } /{ }^{\circ} \mathrm{C}\end{array}$ & $\begin{array}{c}\text { end } \\
\text { temp } /{ }^{\circ} \mathrm{C}\end{array}$ & $T_{\mathrm{g}}{ }^{c} /{ }^{\circ} \mathrm{C}$ \\
\hline polystyrene & 13750 & 94 & 106 & 99 \\
\hline $\begin{array}{l}\text { cellulose- } g \text {-polystyrene, } \\
39 \% \text { graft ratio }\end{array}$ & $14500^{b}$ & 112 & 121 & 116 \\
\hline $\begin{array}{l}\text { cellulose- } g \text {-polystyrene, } \\
30 \% \text { graft ratio }\end{array}$ & $11420^{b}$ & 111 & 118 & 115 \\
\hline $\begin{array}{l}\text { cellulose- } g \text {-polystyrene, } \\
20 \% \text { graft ratio }\end{array}$ & $6570^{b}$ & 108 & 118 & 113 \\
\hline $\begin{array}{l}\text { physical mixture of cellulose } \\
\text { and } 39 \% \text { polystyrene }\end{array}$ & & 97 & 106 & 101 \\
\hline
\end{tabular}

${ }^{a}$ Number-average molecular weight, $M_{\mathrm{n}}$, determined via size-exclusion chromatography, SEC, using tetrahydrofuran, THF, as eluent with polystyrene (PSt) standards. ${ }^{b} M_{\mathrm{n}}$ of PSt grafts cleaved from cellulose- $g$-PSt copolymers. ${ }^{c}$ Glass transition temperature, $T_{\mathrm{g}}$, determined via differential scanning calorimetry, DSC.

sample was cut into approximately $2 \mathrm{~cm} \times 1.8 \mathrm{~cm}$ dimensions with a weight of approximately $0.04 \mathrm{~g}$. Trichoderma reesei cellulase (Fluka) was used as received for the enzymatic hydrolysis of cellulosic materials. Dioxan, methanol $(\mathrm{MeOH})$, tetrahydrofuran (THF), ethanol, and toluene (all Aldrich) were used as received and without further purification.

Size Exclusion Chromatography (SEC) Analysis. The molecular weight distributions were measured via SEC on a Shimadzu modular system, which consisted of an auto injector, a Phenomenex $5.0 \mu \mathrm{m}$ bead-size guard column $(50 \times 7.5 \mathrm{~mm})$ followed by three Phenomenex $5.0 \mu \mathrm{m}$ bead-size columns $\left(10^{5}, 10^{4}\right.$, and $\left.10^{3} \AA\right)$, and a differential refractive-index detector. The eluent was THF $(1 \mathrm{~mL}$ $\min ^{-1}$ ), and the system was calibrated with polystyrene (PSt) standards with molecular weights of 200 to $10^{6} \mathrm{~g} \mathrm{~mol}^{-1}$.

X-ray Photoelectron Spectroscopy (XPS) Measurements. XPS measurements were carried out on a VG ESCALAB220i-XL surface analysis instrument with a mono-chromatized Al $\mathrm{K} \alpha \mathrm{X}$-ray source (1486.6 eV photons) at a constant dwelling time of $100 \mathrm{~ms}$ for several scans and a pass energy of $20 \mathrm{eV}$ for region scan spectra and $100 \mathrm{eV}$ for survey scan spectra. The anode current was 20 $\mathrm{mA}$. The pressure in the analysis chamber was maintained at $2 \times$ $10^{-9}$ Torr or lower during each measurement. The cellulose samples were mounted on the standard sample studs by means of doublesided adhesive tapes. The core-level signals were obtained at the photoelectron takeoff angle ( $\alpha$, with respect to the sample surface) of $90^{\circ}$. All binding energies (BEs) were referenced to the $\mathrm{C} 1 \mathrm{~s}$ hydrocarbon peak at $285 \mathrm{eV}$. In peak synthesis, the line width (full width at half-maximum) for the Gaussian peaks was maintained constant for all components in a particular spectrum. Surface elemental stoichiometries were determined from peak-area ratios, after correcting with the experimentally determined sensitivity factors, and were reliable to $\pm 5 \%$. The elemental sensitivity factors were determined using stable binary compounds of well-established stoichiometries.

Raman Spectroscopy (FT-Raman). Raman spectra of samples were recorded in the frequency range of 50 to $3600 \mathrm{~cm}^{-1}$ using a Bruker IFS 66 spectrometer with a FRA 106/S module. The laser source was a Nd:YAG laser.

Thermogravimetric Analysis (TGA). Thermal decomposition properties of polymers were recorded using a Perkin-Elmer thermogravimetric analyzer (Pyris 1 TGA). Analyses were conducted over the temperature range from 25 to $500{ }^{\circ} \mathrm{C}$ with a programmed temperature increment of $10{ }^{\circ} \mathrm{C} \min ^{-1}$ under $\mathrm{N}_{2}$ atmosphere.

Differential Scanning Calorimetery (DSC). Perkin-Elmer differential scanning calorimeter (DSC 7) and thermal analysis controller (TAC71DX) were used in conjunction to measure glass transition temperatures. The DSC instrument was calibrated with indium and zinc standards of known mass, melting point temperature and known associated enthalpy change. Samples were analyzed in $50 \mu \mathrm{L}$ pans, over the temperature range of 25 to $500{ }^{\circ} \mathrm{C}$ with a scanning rate of $10{ }^{\circ} \mathrm{C} \mathrm{min}-1$ under $\mathrm{N}_{2}$ atmosphere. The initial thermal decomposition temperature, $T_{\mathrm{di}}$, and the maximum 

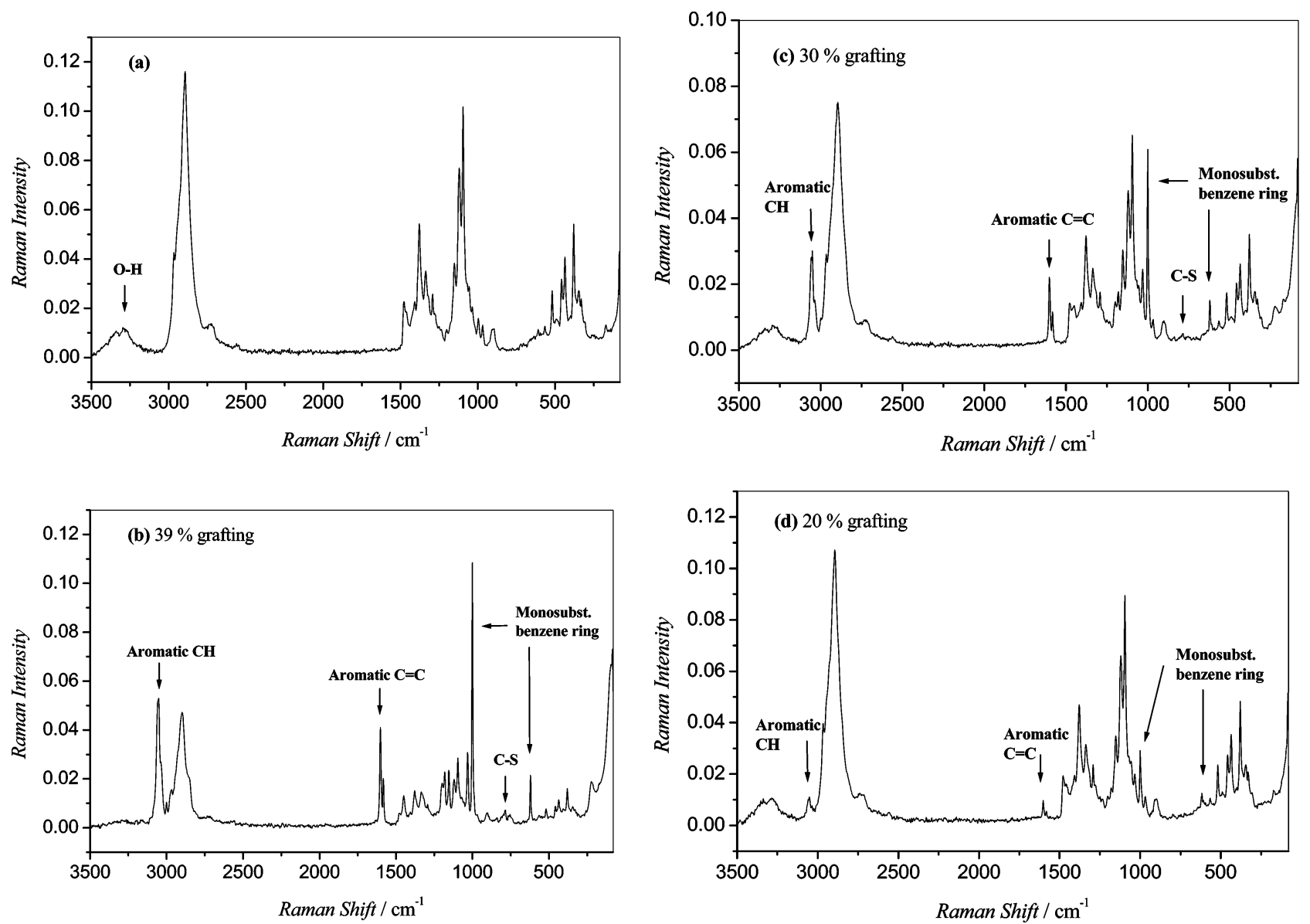

Figure 3. Raman spectra: (a) cellulose; (b) cellulose- $g$-PSt, $39 \%$ graft ratio; (c) cellulose- $g$-PSt, $30 \%$ graft ratio; (d) cellulose- $g$-PSt, $20 \%$ graft ratio.

decomposition temperature, $T_{\mathrm{dm}}$, were determined with the Pyris Data Analysis software.

Scanning Electron Microscopy (SEM). The surface morphology of the cellulose samples before and after grafting was observed by SEM using a Hitachi S900 scanning electron microscope. Samples were sputter-coated with chromium. Electron micrographs of each sample were recorded at different magnifications.

Contact Angle Measurement. The degree of hydrophobicity of cellulose- $g$-polystyrene (cellulose- $g$-PSt) copolymers was appraised using a KSV Cam 200 contact angle meter. A drop of water was placed on the copolymer surface, and the contact angle was determined at $20{ }^{\circ} \mathrm{C}$.

Pretreatment of Cellulose. Pieces of Whatman No. 1 filter paper were first washed with ethanol and subsequently immersed into an aqueous solution $(250 \mathrm{~mL})$ of $10 \mathrm{wt} \% \mathrm{NaOH}$ to break down the extensive hydrogen bonding between the $\mathrm{OH}$ groups of cellulose and to open up the ordered regions, so that the reagents could easily penetrate inside the cellulose substrate. The samples were placed on a shaker and shaken for $24 \mathrm{~h}$ at ambient temperature. The swollen cellulose samples were repeatedly washed with absolute ethanol until a neutral solution was achieved. The use of ethanol for washings prevents the formation of extensive interchain hydrogen bonds and results in a higher reactivity of cellulose toward grafting reactions. ${ }^{39}$ Ethanol in the cellulose samples was then displaced by the proper polymerization solvent $(5 \times 50 \mathrm{~mL})$, and the filter papers were directly used for graft polymerizations without any drying. Grafting experiments using cellulose without pretreatment were also performed. The graft ratio of the cellulose samples without pretreatment was significantly lower (e.g., less than 4\%) than the pretreated ones.

Polymerization. Polymerizations were performed in three solvents $(60 \%$ (v/v) to monomer); $\mathrm{MeOH}$, toluene and dioxanwater mixture. In the case of homopolymerizations, cellulose was not added to the sample vials. The reaction mixture (styrene, CPDA, and solvent) were filled into vials which were subsequently capped with rubber septa and deoxygenated through purging with nitrogen for $20 \mathrm{~min}$ each. The samples were placed in a shielded irradiation room with a ${ }^{60} \mathrm{Co}$ source at ambient temperature at a dose rate of $0.09 \mathrm{kGy} \mathrm{h}^{-1}$. Samples were taken from the chamber at different time intervals. The conversion of each sample was determined gravimetrically after drying initially in a fume hood and then in a vacuum oven at $30{ }^{\circ} \mathrm{C}$ for 3 days. ${ }^{1} \mathrm{H}$ NMR spectroscopy was used to verify the complete removal of residual monomer. The crude cellulose- $g$-PSt copolymer samples were repeatedly washed with toluene and THF to remove surface contaminations. Each cellulosic copolymer was subsequently placed in a bottle, and $50 \mathrm{~mL}$ of THF was added. The bottles were placed on a shaker and shaken for several days (up to 2 weeks). The solvent was changed every day. This process was repeated until no homo-PSt could be identified in the rinsing solution via SEC analysis (after complete evaporation of the solvent). Finally, the cellulose- $g$-PSt sample was dried to a constant weight under vacuum at $45^{\circ} \mathrm{C}$. The graft ratio $(G$, wt $\%)$ was calculated using the following equation:

$$
G=\frac{W_{2}-W_{1}}{W_{1}} \times 100
$$

where $W_{1}(\mathrm{~g})$ is the weight of the native cellulose and $W_{2}(\mathrm{~g})$ is the dry weight of the cellulose- $g$-PSt sample. Conversion (\%) in the solution was taken as the fraction of the monomer that polymerized and was determined via gravimetry. The overall conversion (\%)that is the conversion in the solution and the PSt grafted from the cellulose-was calculated using the following equation:

$$
\frac{\left(W_{2}-W_{1}\right)+W\left(P S t_{\text {free }}\right)}{W(\text { monomer })} \times 100=\text { overall conversion }
$$


where $\mathrm{W}\left(\mathrm{PSt}_{\text {free }}\right)(\mathrm{g})$ is the weight of the PSt formed in the solution, and $\mathrm{W}$ (monomer) ( $\mathrm{g}$ ) is the weight of the initial monomer.

The theoretical, number-average molecular weight, $M_{\mathrm{n}}^{\text {th }}$, was calculated according to the following equation:

$$
M_{\mathrm{n}}^{\text {th }}=M_{\mathrm{CTA}}+\frac{n_{\mathrm{m}}^{0} M_{M}}{n_{\mathrm{CTA}}^{0}} \times \text { overall conversion }
$$

where $M_{\mathrm{n}}^{\text {th }}$ is the theoretical number-average molecular weight of the polymer, $n_{\mathrm{m}}^{0}$, the number of moles of the monomer initially present in the system, $M_{\mathrm{M}}$, the molecular weight of the monomer, $n_{\mathrm{CTA}}^{0}$, the number of moles of CTA initially present in the system, and $M_{\mathrm{CTA}}$, the molecular weight of the CTA.

In a typical graft polymerization, the reaction solution was prepared by dissolving styrene $(3.6 \mathrm{~mL}, 31.1 \mathrm{mmol})$ and CPDA $(0.013 \mathrm{~g}, 0.045 \mathrm{mmol})$ in $5.4 \mathrm{~mL}$ of $\mathrm{MeOH}$, toluene or dioxanwater mixture $(5.2 \mathrm{~mL}$ dioxan, $0.2 \mathrm{~mL}$ water; $2 \%$ of the total solution volume is water). The reaction solution was subsequently added to a glass sample vial containing $0.0389 \mathrm{~g}$ of pretreated cellulose. The molar ratio of monomer and CTA was 690:1. The sample was degassed and subsequently irradiated for $232 \mathrm{~h}$ at ambient temperature at a dose rate of $0.09 \mathrm{kGy} \mathrm{h}^{-1}$. The weight of the cellulose- $g$-PSt sample was $0.0541 \mathrm{~g}$, the grafting ratio calculated via eq 1 was $39.1 \%$. The weight of the free PSt in the solution was $0.6274 \mathrm{~g}$. The overall conversion calculated via eq 2 was $19.7 \%$. The number-average molecular weight of the free PSt was $13.750 \mathrm{~g} \mathrm{~mol}^{-1}$. The glass transition temperature of the cellulose- $g$-PSt sample was $116^{\circ} \mathrm{C}$.

Cleaving of PSt from Cellulose Backbone. PSt was cleaved from the cellulose surface under acidic conditions. $0.06 \mathrm{~g}$ of grafted cellulose was allowed to swell for $24 \mathrm{~h}$ in $10 \mathrm{~mL}$ of a mixture of acetone, dimethylformamide and water (15:4:1). An equal portion of $37 \% \mathrm{HCl}$ was added to the reaction medium and the mixture was diluted with THF to be $25 \%$ in $\mathrm{HCl}$. The mixture was refluxed and stirred at $80{ }^{\circ} \mathrm{C}$ for up to 3 weeks until the cellulose was completely hydrolyzed, leading to a homogeneous brown solution. Following the completion of the reaction, the solvent mixture was evaporated using a rotary evaporator and dried at $50{ }^{\circ} \mathrm{C}$ in a vacuum oven. The resulting viscous liquid was dissolved in toluene (10 $\mathrm{mL}$ ) and then extracted twice with distilled water $(15-20 \mathrm{~mL})$. The organic phase was dried with anhydrous sodium sulfate for 24 h. After filtration of the sodium salt, PSt was collected by complete evaporation of the solvent. The viscous PSt product was then dissolved in THF and analyzed by SEC. The number-average molecular weight of the cleaved PSt of the above-mentioned sample was $14.500 \mathrm{~g} \mathrm{~mol}^{-1}$.

Enzymatic Hydrolysis Analysis. In order to study the differences in enzymatic hydrolysis behavior of native and grafted cellulose samples, cellulose- $g$-PSt copolymer and native cellulose was incubated with $T$. reesei cellulase enzyme. $T$. reesei cellulase enzyme $(0.3 \mathrm{mg})$ was added to $12 \mathrm{~mL}$ of $20 \mathrm{mM}$ sodium acetate buffer, $\mathrm{pH} 5.0$, at $37{ }^{\circ} \mathrm{C}$. $0.06 \mathrm{~g}$ of cellulosic compound, i.e., cellulose- $g$-PSt copolymer or native cellulose, was then immersed into this solution. The incubation mixtures were left in a Ratek Orbital Mixer Incubator at $37{ }^{\circ} \mathrm{C}$ for up to 7 days.

\section{Results and Discussion}

Synthesis and Characterization of Cellulose-g-PSt Copolymers.

Polymerizations. Cellulose is a nonbranched condensation polymer consisting of D-anhydro glucose units joined together by $\beta$-1,4-linkage. Cellulose exhibits a high degree of crystallinity in its native state and there are strong intermolecular hydrogen bonds between adjacent cellulose chains via the hydroxyl groups. Therefore, the $\mathrm{OH}$ groups of cellulose are not easily accessible for reactions. In polar solvents, especially in low molecular weight alcohols such as $\mathrm{MeOH}$, the hydrogen bonds among the cellulose units are cleaved and the more ordered regions are opened up. ${ }^{4}$ Consequently, reagents can easily penetrate into
Table 2. Thermostability of Cellulose, Polystyrene, and Cellulose- $g$-polystyrene Copolymers

\begin{tabular}{|c|c|c|c|c|}
\hline sample & $\begin{array}{l}M_{\mathrm{n}}{ }^{a} / \mathrm{g} \\
\mathrm{mol}^{-1}\end{array}$ & $T_{\mathrm{di}}{ }^{c} /{ }^{\circ} \mathrm{C}$ & $T_{\mathrm{dm}}{ }^{d /{ }^{\circ} \mathrm{C}}$ & $\begin{array}{c}\text { residual } \\
\text { mass/wt } \%\end{array}$ \\
\hline cellulose & & 288 & 361 & 11.36 \\
\hline $\begin{array}{l}\text { cellulose- } g \text {-polystyrene, } \\
39 \% \text { graft ratio }\end{array}$ & $14500^{b}$ & 294 & $367,425^{e}$ & 2.95 \\
\hline $\begin{array}{l}\text { cellulose- } g \text {-polystyrene, } \\
20 \% \text { graft ratio }\end{array}$ & $6570^{b}$ & 292 & $366,413^{e}$ & 7.05 \\
\hline polystyrene & 13750 & 344 & 410 & 0.10 \\
\hline
\end{tabular}

${ }^{a}$ Number-average molecular weight, $M_{\mathrm{n}}$, determined via size-exclusion chromatography, SEC, using tetrahydrofuran, THF, as eluent with polystyrene (PSt) standards. ${ }^{b} M_{\mathrm{n}}$ of PSt grafts cleaved from cellulose- $g$-PSt copolymers. ${ }^{c}$ The initial thermal decomposition temperature, $T_{\mathrm{di}}$, is the temperature at which the decomposition rate points out a significant weight loss $\left(\mathrm{d}(\mathrm{wt} \%) / \mathrm{d} T>1 \%{ }^{\circ} \mathrm{C}^{-1}\right) .{ }^{d}$ The maximum decomposition temperature, $T_{\mathrm{dm}}$, is the temperature at which the highest decomposition rate is observed for the corresponding pattern. ${ }^{e}$ In the case of cellulose- $g$-PSt copolymers, the first tabulated value corresponds to the $T_{\mathrm{dm}}$ for cellulose decomposition, whereas the latter is that for the decomposition of PSt.

the cellulose substrate leading to more efficient modification and higher graft ratios.

Application of $\gamma$-radiation (e.g., from a ${ }^{60} \mathrm{Co}$ source) generates radicals on the cellulose surface and in the monomer solution. Subsequently, monomer radicals and radicals formed on the surface initiate propagating chains, which then add to the thiocarbonyl group of the RAFT agent. Styrene was chosen for this study not only because it is stable under the acidic conditions used for the hydrolysis of cellulose, but also because its freeradical radiation chemical yield $\left(G_{\mathrm{R}}\right)$ is lower that that of cellulose. In general, grafting from a polymer is preferred over homopolymerization of the monomer if the free-radical yield of the polymer to be grafted is much larger than that of the monomer. ${ }^{40}$ The average value of the $G_{\mathrm{R}}$ of styrene $\left[G_{\mathrm{R}}-\right.$ (styrene)] is 0.69 radicals per $100 \mathrm{eV}^{40}$ whereas this value is 2.88 radicals per $100 \mathrm{eV}$ for cellulose $\mathrm{e}^{41}$ at room temperature. Therefore, grafting of styrene from cellulose is-in generalfavored over the homopolymerization of styrene.

For the present investigation, it is also desirable to achieve high grafting ratios: The grafted cellulose is subjected to acid hydrolysis and the obtained PSt is subsequently analyzed via SEC. Therefore, high graft ratios are beneficial for the subsequent analysis. In our recent work we obtained low conversion values (e.g., 9\%) for styrene in bulk-initiated via $\gamma$-radiation and mediated via CPDA-after long irradiation times (e.g., 80 h) ${ }^{34}$ Inspection of the literature shows that high graft ratios of PSt were achieved in MeOH. ${ }^{4}$ Dilli and Garnet studied the radiation-induced grafting of St from cellulose in $\mathrm{MeOH}$ and investigated the effects of monomer concentration, radiation dose and rate on the graft ratios. They found that the graft ratio-in general-was higher for $30-50 \%$ monomer concentrations. Among the graft ratios they observed, the maximum graft ratio was $182 \%$ at $40 \%$ monomer and $1.56 \mathrm{Mrad}$ dose. The polymerizations were therefore first carried out in $\mathrm{MeOH}$, although it is a precipitating agent for PSt. We found that even at very low conversions (around 5\%) the polymerization solution started to become cloudy and heterogeneous, and subsequently at higher values (around $8 \%$ conversion) PSt precipitated. However, very satisfying graft ratios were achieved in $\mathrm{MeOH}$ (the maximum graft ratio was $55 \%$ when the conversion was $24 \%$ at $9.36 \mathrm{kGy}$ dose). Analysis of the nongrafted PSt via SEC showed multimodal chromatograms and no control of the polymerization. Therefore, we subsequently used toluene for the polymerizations since the controlled character of styrene polymerization via RAFT is well established in this solvent. ${ }^{28}$ The results of SEC analysis showed that the polymerization in 

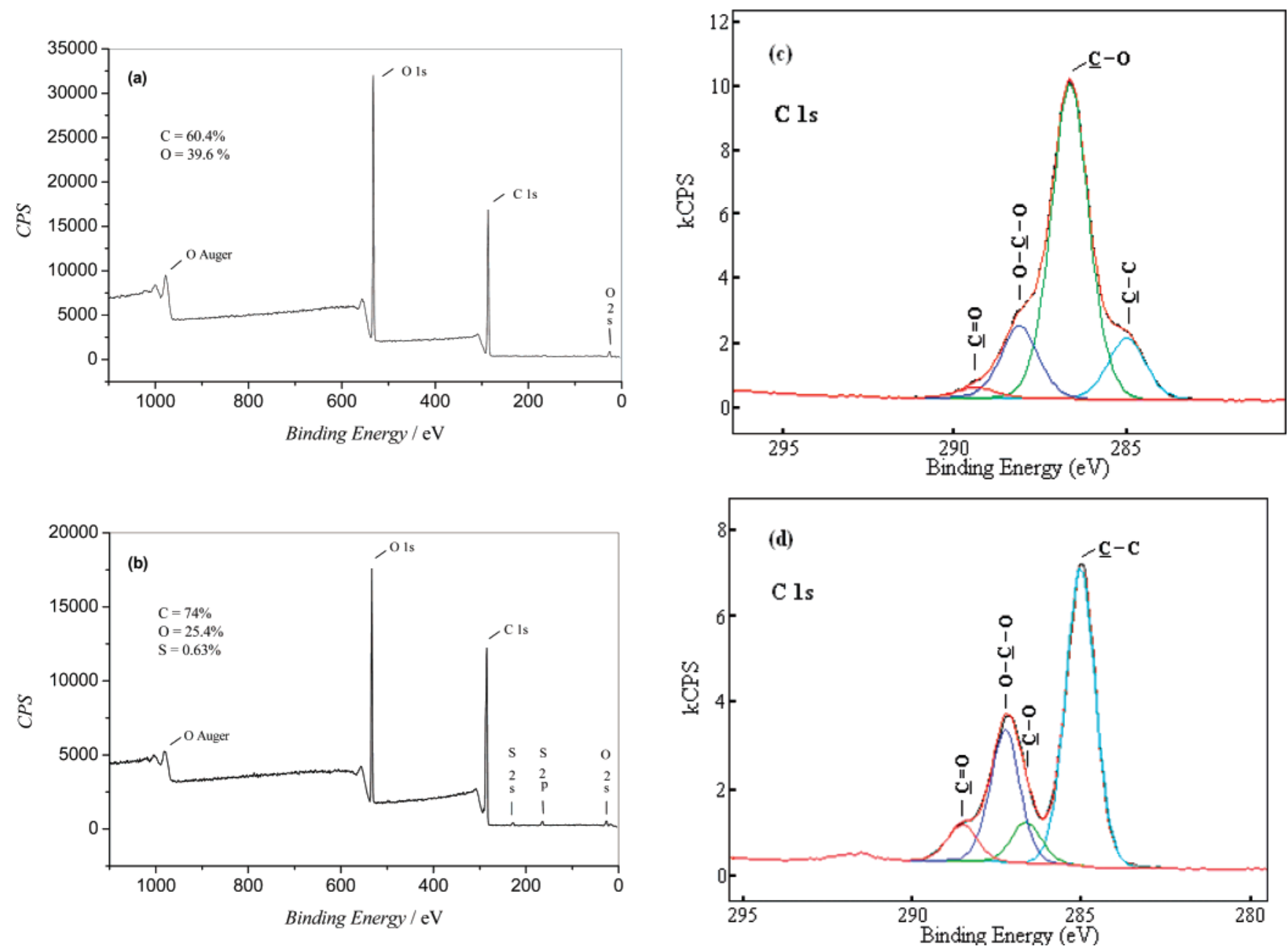

Figure 4. XPS spectra: (a) survey wide scan of native cellulose, (b) survey wide scan of cellulose- $g$-PSt copolymer with graft ratio of $39 \%$, (c) $\mathrm{C}$ 1s spectrum and its components of native cellulose, (d) C 1s spectrum and its components of cellulose- $g$-PSt copolymer with graft ratio of $39 \%$.

toluene was controlled. However, the grafting was very low; the maximum graft ratio was just $3 \%$ when the conversion was $10 \%$ at $9.36 \mathrm{kGy}$ dose. This low graft ratio may be due to a (premature) transfer reaction of the surface-bond radicals with toluene. This transfer to solvent subsequently decreases the number of polymer chains that can be grafted to the surface as the number of "attachment points" on the surface are reduced, resulting in a lower graft ratio. In addition, toluene is an apolar solvent and therefore the hydrogen bonds among the cellulose may be formed again, leading to a reduced surface area for grafting. Because of the insufficient grafting obtained in toluene, we performed the polymerizations in a polar solvent mixture of dioxan-water ( $2 \%$ of the total solution volume is water). The $2 \%(\mathrm{v} / \mathrm{v})$ water is compatible with producing homogeneous solutions as well as helping cellulose to swell, while still allowing solubility of PSt produced during irradiation. ${ }^{42}$ In addition to obtaining satisfying graft ratios (max. 39\% grafting), controlled polymerization was also observed in dioxan-water mixture using CPDA as the RAFT agent, styrene as the monomer, and $\gamma$-radiation as the source of initiation. This is demonstrated in Figure 1, where the linear evolution of the number-average molecular weight, $M_{\mathrm{n}}$, with conversionexpected for a controlled polymerization-is depicted. Furthermore, the polydispersity index (PDI, i.e., the ratio of weightaverage molecular weight, $M_{\mathrm{w}}$, to $\left.M_{\mathrm{n}}\right)$ remains low $(<1.25)$ throughout the duration of the polymerization. The agreement with the theoretical number-average molecular weight, $M_{\mathrm{n}}^{\text {th }}$, (calculated by eq 3 ) is also excellent.
The full molecular weight distributions obtained at different times are depicted in Figure 2 for the nongrafted PSt formed during the graft polymerizations.

We also investigated the influence of the added cellulose on the styrene polymerization: Styrene homopolymerization initiated via $\gamma$-radiation and mediated via CPDA was performed in dioxane-water without the addition of cellulose. (The same (identical) solution was used for the homopolymerization and graft polymerization.) The homopolymerization of styrene without cellulose substrate also demonstrated a controlled character (see Supporting Information, Figures $2 \mathrm{~S}$ and 3S). Comparison of the styrene polymerization with and without cellulose shows that the addition of cellulose leads to higher conversions at the same time and therefore higher molecular weights: e.g., polymerization without cellulose results in a conversion of $4.11 \%$ and a $M_{\mathrm{n}}$ of $2230 \mathrm{~g} \mathrm{~mol}^{-1}$ after $72 \mathrm{~h}$, polymerization with cellulose results in a conversion of $7.06 \%$ and a $M_{\mathrm{n}}$ of $4740 \mathrm{~g} \mathrm{~mol}^{-1}$ after $72 \mathrm{~h}$ (see Supporting Information, Table 1S). As mentioned above, the $G_{\mathrm{R}}$ value of cellulose is higher than that of styrene. Therefore, addition of cellulose to the reaction mixture leads to the generation of more radicals that can start the polymerization which results in a higher conversion and therefore higher $M_{\mathrm{n}}$ (see also eq 3 ).

Raman Analysis. Raman spectra and the analysis of characteristic shifts of cellulose (Figure 3 a) and cellulose- $g$-PSt copolymers (of different graft ratios, Figure $3 b-d$ ) are shown in Figure 3. 

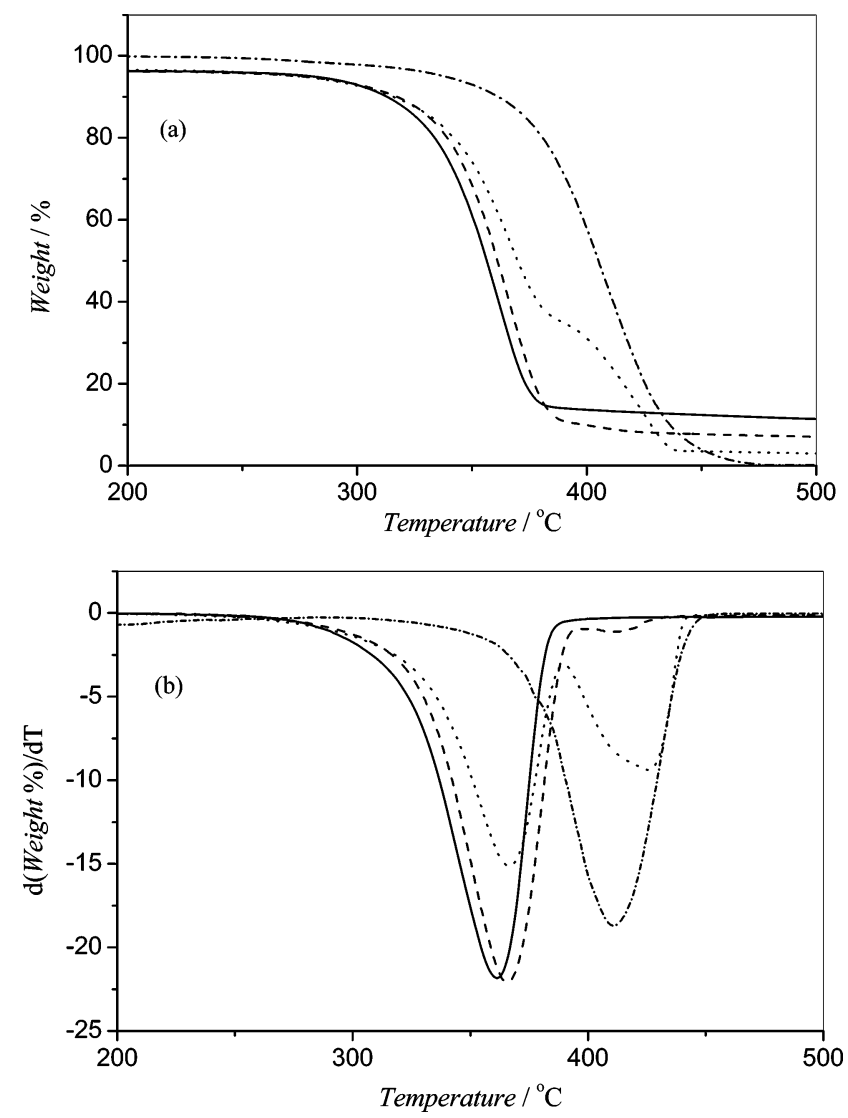

Figure 5. (a) Thermogravimetry and (b) derivative thermogravimetry curves of $(-)$ cellulose; $(-\cdot-)$ PSt; $(\cdots)$ cellulose- $g$-PSt, 39\% graft ratio; $(--)$ cellulose- $g$-PSt, $20 \%$ graft ratio.

Inspection of Figure 3, parts b-d shows bands at $996 \mathrm{~cm}^{-1}$, characteristic of PSt (C-C ring "breathing" vibration), ${ }^{43}$ inplane $\mathrm{CH}$ bending vibration at $1032 \mathrm{~cm}^{-1}$, intense $\mathrm{C}=\mathrm{C}$ stretching vibration at $1603 \mathrm{~cm}^{-1}$, in-plane ring bending at 622 $\mathrm{cm}^{-1}$ and aromatic $\mathrm{CH}$ stretching at $3053 \mathrm{~cm}^{-1}$. This illustrates the successful grafting between cellulose and PSt. As can be seen in Figure 3, the intensity of these Raman bands increase proportionally with the amount of styrene grafted from the surface of the cellulose substrate. ${ }^{44}$ Furthermore, the Raman shift at $787 \mathrm{~cm}^{-1}$, corresponding to $\mathrm{C}-\mathrm{S}$ stretching, ${ }^{45,46}$ shows the presence of the RAFT end groups of the grafted PSt, which indicates that polymerizations occurred via the RAFT mechanism.

X-ray Photoelectron Spectroscopy (XPS) Analysis. The surface compositions of cellulose and cellulose- $g$-PSt copolymer with $39 \%$ graft ratio were studied by XPS. Figure 4 shows the survey wide scan and $\mathrm{C}$ 1s spectra of the native and grafted cellulose.

The surface chemical compositions calculated using the peak areas of the XPS spectra are inserted to the survey wide scans. As can be seen from these values, the amount of carbon atoms for the cellulose- $g$-PSt copolymer increases from $60.4 \%$ to $74 \%$ whereas the amount of oxygen atoms decreases from $39.6 \%$ to $25.4 \%$ due to the PSt grafted from the cellulose. The change is more evident in the $\mathrm{C}$ 1s spectra: The $\mathrm{C} 1 \mathrm{~s}$ spectrum of native cellulose consists of a main peak with a bonding energy (BE) of $286.5 \mathrm{eV}$ attributed to $\mathrm{C}-\mathrm{O}$ bonds. However with grafting, the main peak appears at $285 \mathrm{eV}$, attributed to $\mathrm{C}-\mathrm{C}$ bonds. This change indicates the grafting of PSt from cellulose. As can be seen in Figure $4 b, S 2 s$ and $S 2 p$ peaks also appear in the survey wide scan of cellulose- $g$-PSt, which indicates the presence of the RAFT end group of PSt. (a)

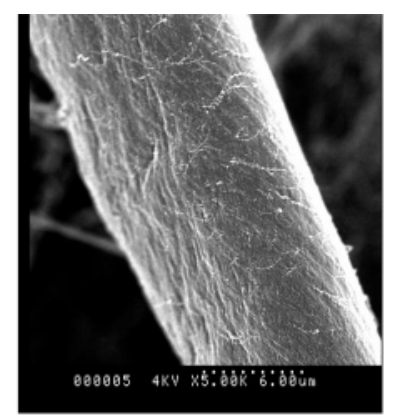

(b)
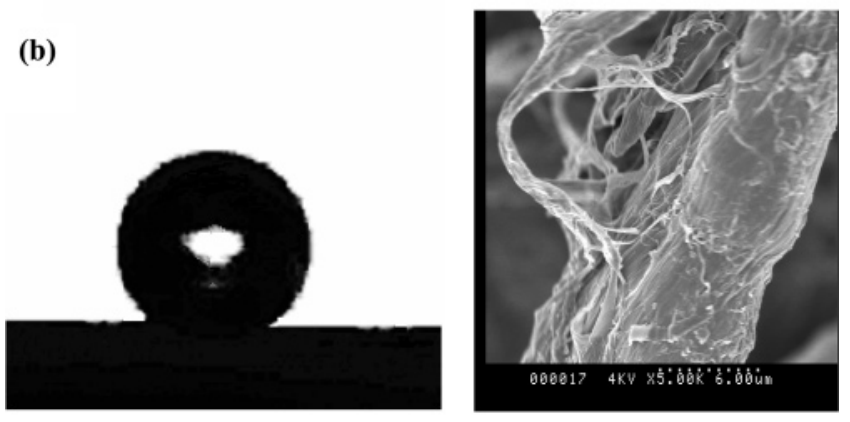

(c)
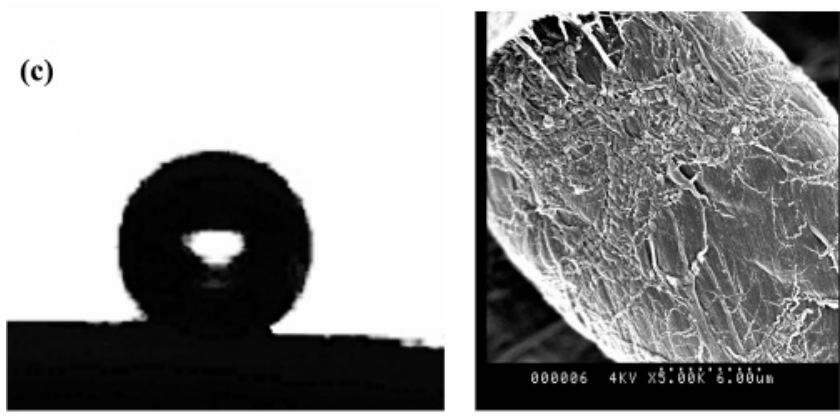

(d)
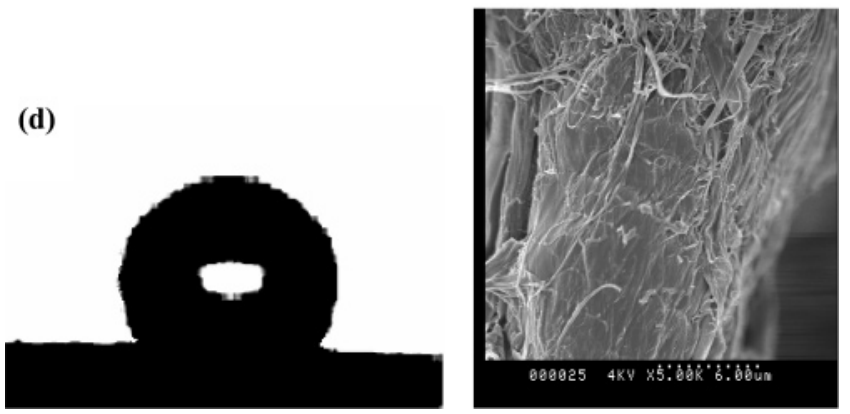

Figure 6. SEM photomicrographs: (a) native cellulose; (b) water contact angle $138^{\circ}$ (left) and corresponding SEM photomicrograph of cellulose- $g$-PSt, $39 \%$ grafting; (c) water contact angle $134^{\circ}$ (left) and corresponding SEM photomicrograph of cellulose- $g$-PSt, $30 \%$ grafting; (d) water contact angle $123^{\circ}$ (left) and corresponding SEM photomicrograph of cellulose- $g$-PSt, $20 \%$ grafting.

Thermal Analysis. DSC was used for studying the thermal transitions occurring in the course of heating under an inert atmosphere. As presented in Table 1, the PSt $\left(M_{\mathrm{n}}=13750 \mathrm{~g}\right.$ $\mathrm{mol}^{-1}$, PDI $=1.23$ ) sample synthesized via RAFT polymerization, shows one thermal transition at around $99{ }^{\circ} \mathrm{C}$, which corresponds to the glass transition temperature $\left(T_{\mathrm{g}}\right)$ of this polymer. The cellulose- $g$-PSt samples also exhibit a single thermal transition, but at a higher temperature than that of PSt, at around $115{ }^{\circ} \mathrm{C}$, (see Table 1, see Supporting Information, Figure 1S, for whole DSC thermograms). Since cellulose does not exhibit a $T_{\mathrm{g}}$, the transition observed here should be due to the $T_{\mathrm{g}}$ of PSt grafted from the cellulose substrate.

Table 1 also shows the $M_{\mathrm{n}}$ values of PSt cleaved from the cellulose- $g$-PSt copolymers used in the DSC studies. The 


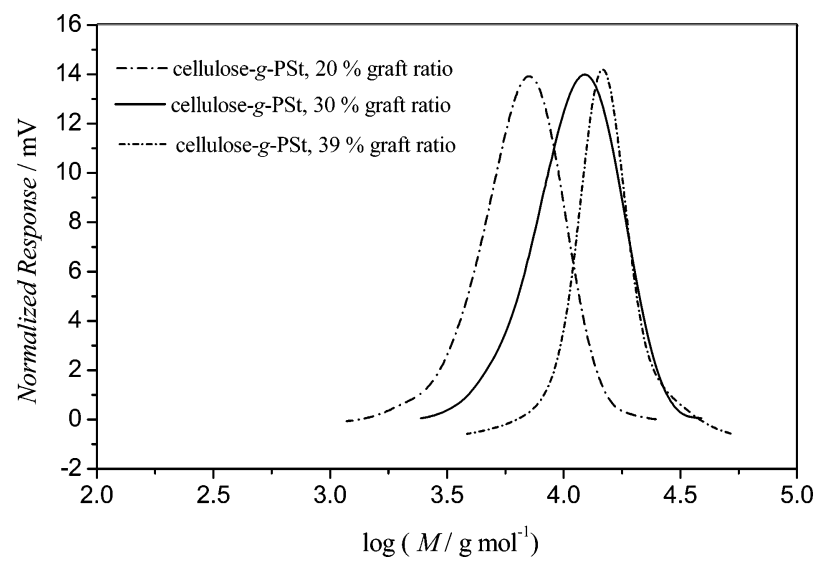

Figure 7. SEC chromatograms of polystyrene cleaved from the cellulose substrate formed during $\gamma$-initiated graft polymerization from cellulose mediated via the RAFT agent cumyl phenyldithioacetate (CPDA): $[\mathrm{St}]=3.45 \mathrm{~mol} \mathrm{~L}^{-1}$, cellulose $(0.04 \mathrm{~g})$, dose rate $0.09 \mathrm{kGy}$ $\mathrm{h}^{-1}$, in dioxane-water $(98: 2 \mathrm{v} / \mathrm{v}),[\mathrm{St}] /[\mathrm{CPDA}]=690: 1$, at room temperature.

increase in $T_{\mathrm{g}} \mathrm{S}$ of the copolymer samples is attributed to the restricted mobility of PSt chains grafted from the cellulose surface; this effect cannot be explained using the difference in $M_{\mathrm{n}}$ values. However, the slight change observed among the $T_{\mathrm{g}} \mathrm{s}$ of copolymers is probably caused by the difference in molecular weights of the PSt grafts. A physical mixture of PSt and cellulose-having 39\% PSt in weight-showed a different thermal transition $\left(101{ }^{\circ} \mathrm{C}\right)$ from those obtained for cellulose- $g$-PSt copolymers. The thermal transition at $101{ }^{\circ} \mathrm{C}$ is compatible with the $T_{\mathrm{g}}$ of homo-PSt (e.g., nongrafted PSt). This observation confirms the covalent grafting of PSt chains from the surface of cellulose, and restriction imposed on the segmental motion of the PSt chains as a result of grafting.

TGA was performed to study the decomposition pattern and thermal stability of the graft copolymers. Thermogravimetry (TG) and derivative thermogravimetry (DTG) curves of cellulose, PSt $\left(M_{\mathrm{n}}=13750 \mathrm{~g} \mathrm{~mol}^{-1}\right.$, PDI $\left.=1.23\right)$ and cellulosic copolymers with different graft ratios are shown in Figure 5, the data are summarized in Table 2.

TG and DTG curves show that the degradation profile of the grafted samples contains two steps; the first is due to the degradation of cellulose whereas the latter is due to PSt degradation. From the results in Table 2, it can be seen that both the initial decomposition $\left(T_{\mathrm{di}}\right)$ and the maximum decomposition $\left(T_{\mathrm{dm}}\right)$ temperatures of cellulose- $g$-PSt copolymers are higher than those of native cellulose, indicating the increased thermal stability of cellulose after grafting. The second step attributed to PSt decomposition also shifted to higher $T_{\mathrm{dm}}$ values for the copolymers compared to that of pure PSt, which illustrates the covalent attachment of PSt to cellulose. ${ }^{28,47}$ Furthermore, an increase in degradation temperature for the second step is observed with an increase of the PSt content in the copolymer as has been reported by Roy et al. ${ }^{28}$

Scanning Electron Microscopy. SEM micrographs of native cellulose and cellulose- $g$-PSt copolymers are shown in Figure 6. The structural features of the cellulosic copolymers are different than that of the native cellulose since the grafting occurs mainly at the surface of cellulose. The surface coverage of cellulose by PSt increases with increasing graft ratio.

Water Contact Angle. Surface characterization of cellulose via water contact angle (CA) measurement is not straightforward due to the inherent roughness and the adsorbing nature of the cellulose surface. Therefore, CA measurements can only be considered conjectures of the surface properties. ${ }^{22}$ The virgin
Table 3. Number-Average Molecular Weight, and Polydispersity Indices for Free and Cleaved Polystyrene Polymerized via $\gamma$-Initiated Reversible Addition Fragmentation Chain Transfer Polymerization from Cellulose $^{a}$

\begin{tabular}{ccccccc}
\hline & & $\begin{array}{c}\text { graft } \\
\text { ratio/ } \\
\text { wt } \%^{b}\end{array}$ & $\begin{array}{c}M_{\mathrm{n}} / \mathrm{g} \\
\mathrm{mol}^{-1} \\
\mathrm{free} \mathrm{PSt}^{c}\end{array}$ & $\begin{array}{c}\mathrm{PDI} \mathrm{free}_{\mathrm{PSt}^{c}} \\
\text { time/h }\end{array}$ convn/\% $^{b}$ & $\begin{array}{c}M_{\mathrm{n}} / \mathrm{g} \mathrm{mol}^{-1} \\
\text { cleaved PSt }^{d}\end{array}$ & $\begin{array}{c}\text { PDI } \\
\text { cleaved } \\
\mathrm{PSt}^{d}\end{array}$ \\
\hline 96 & 9.18 & 20.10 & 6050 & 1.24 & 6570 & 1.18 \\
160 & 16.50 & 30.00 & 10760 & 1.21 & 11420 & 1.18 \\
232 & 19.70 & 39.10 & 13750 & 1.23 & 14500 & 1.13
\end{tabular}

${ }^{a}$ Reversible addition fragmentation chain transfer (RAFT) polymerization of styrene $\left(3.45 \mathrm{~mol} \mathrm{~L}^{-1}\right)$ from cellulose $(0.04 \mathrm{~g})$ initiated via $\gamma$-irradiation $\left(\right.$ dose rate, $\left.0.09 \mathrm{kGy} \mathrm{h}^{-1}\right)$ in dioxane-water $(98: 2 \mathrm{v} / \mathrm{v})$ at $[\mathrm{St}] /[\mathrm{CPDA}]=$ 690:1 and room temperature. ${ }^{b}$ Monomer conversion and graft ratio determined gravimetrically. ${ }^{c}$ Number-average molecular weight, $M_{\mathrm{n}}$, and polydispersity index, PDI, determined via size-exclusion chromatography, SEC, using tetrahydrofuran, THF, as eluent with polystyrene (PSt) standards for free PSt formed during the graft polymerization of styrene from cellulose.

${ }^{d} M_{\mathrm{n}}$ and PDI for PSt grafts cleaved from the surface of cellulose after acidic hydrolysis.

filter paper adsorbs water very quickly, rendering measurement of the contact angle impossible. However, the cellulose- $g$-PSt samples having graft ratios of $20 \%, 30 \%$, and $39 \%$ became very hydrophobic with CAs of 123,134 , and $138^{\circ}$ (see Figure 6), respectively. It was observed that the water droplet was partly absorbed beneath the surface after a period of time; the CA decreased to 94,103 , and $110^{\circ}$ after $50 \mathrm{~min}$ for the abovementioned cellulosic copolymers, respectively. Afterward, no more water absorption could be detected for the samples, suggesting sufficient surface coverage.

Cleaving of the PSt Grafts from the Cellulose Surface. Assessment of the Enzymatic Hydrolysis of Cellulosic Materials. Enzymatic hydrolysis of the cellulosic materials was studied using $T$. reesei cellulase enzyme. Native cellulose was dissolved into free fibers after being immersed in a solution containing the cellulase enzyme for $24 \mathrm{~h}$. At the end of the third day, native cellulose was completely hydrolyzed. However, cellulose- $g$-PSt copolymer with $39 \%$ graft ratio was still intact even after 3 weeks. Therefore, it is impossible to cleave the PSt grafts from the surface by enzymatic hydrolysis. This indicates that the grafted PSt chains are efficiently covering the surface of the cellulose, protecting it from being attacked by the enzyme.

Acidic Hydrolysis of Cellulosic Substrate. Due to the importance of surface modification and controlled/living polymerization methods, studies containing both subjects have received much attention over the past years to synthesize welldefined grafted materials. In some of these studies, the individual grafts were cleaved from the polymer backbones to determine the degree of control of the free radical grafting process. ${ }^{28,48,49,50}$ However, in all these studies the surfaces had already been modified with suitable functionalities (e.g., RAFT agent, or ATRP initiator) prior to the grafting process which allows the grafted polymer chains to be grown from the polymer backbone in a controlled manner. Another benefit of these prior modifications was to facilitate the cleaving of the grafts by enriching the polymer backbones with suitable chemical functionalities (e.g., ester and ether bonds on the surface). To the best of our knowledge, there is no study in the literature verifying the control of the free radical grafting process without prior modifications of the surface. This has been the main motivation of the present study since determining the degree of control of the grafting from an unmodified surface would be valuable in terms of verifying the controlled character of a "grafting from" approach via the RAFT technique.

When the native cellulose was allowed to the acidic conditions it was quickly hydrolyzed, leading to a homogeneous brown 
solution, while it was necessary to wait for 3 weeks for the complete hydrolysis of the cellulose- $g$-PSt copolymers due to their highly hydrophobic character. In most cases, the amount of cleaved PSt was too low for analysis. In the case of copolymers with graft ratios of $20 \%, 30 \%$, and $39 \%$, cleaved PSt was successfully analyzed by SEC (Figure 7).

Table 3 compares the $M_{\mathrm{n}}$ and PDI values of cleaved PSt with those values of free (nongrafted) PSt existing in the grafting medium.

As can be seen from Table 3, as well as having low PDIs, the $M_{\mathrm{n}}$ values of cleaved PSt are also very close to the values of the corresponding free PSt, and thus to the theoretical molecular weight values. This clearly shows that the radical graft RAFT polymerization of styrene from the surface of cellulose without any prior modification of the cellulose substrate is a controlled process. It is therefore also a valid approach to analyze the free (nongrafted) polymer to gain information on the molecular weight and PDI of the grafted polymer. This finding is of extremely high significance as cleaving of the grafted polymer from surfaces is often impossible or very time-consuming.

Conclusions. Styrene was successfully grafted from cellulose by the combination of radiation-induced initiation and the RAFT technique, leading to highly hydrophobic surfaces. The RAFT agent CPDA was used and the polymerization was performed in a mixture of dioxane-water. The PSt grafts grown from the surface were cleaved by acidic hydrolysis of the cellulose substrate. The free (nongrafted) PSt and the cleaved grafts had almost the same $M_{\mathrm{n}}$ (nearly theoretical $M_{\mathrm{n}}$ ) and PDI. The $M_{\mathrm{n}}$ of the grafted as well as the nongrafted PSt increased linearly with monomer conversion and the polydispersities were narrow. These are first results verifying the control of the $\gamma$-initiated, free radical grafting via the RAFT technique without prior modification of the surfaces.

Acknowledgment. M.B. is grateful to the Australian Government Department of Education, Science and Training (DEST) for an Endeavour Postgraduate Award. We would also like to thank Mr. Istvan Jacenyik for his excellent management of the CAMD. C.B.-K acknowledges receipt of an ARC Australian Professorial Fellowship and T.P.D acknowledges an ARC Federation Fellowship.

Supporting Information Available: Figures showing DSC curves, the evolution of number-average molecular weight, $M_{\mathrm{n}}$, and polydispersity index, PDI, with the monomer conversion, and the evolution of molecular weight distribution with time for the free polystyrene and a table summarizing and comparing the polymerization results and graft ratios. This material is available free of charge via the Internet at http://pubs.acs.org.

\section{References and Notes}

(1) Klemm, D.; Heublein, B.; Fink, H.-P.; Bohn, A. Angew. Chem. Int. Ed. 2005, 44, 3359-3393.

(2) Heinze, T.; Liebert, T. Prog. Polym. Sci. 2001, 26, 1689-1762.

(3) Edgar, K. J.; Buchanan, C. M.; Debenham, J. S.; Rundquist, P. A.; Seiler, B. D.; Shelton, M. C.; Tindall, D. Prog. Polym. Sci. 2001, 26 , $1605-1688$.

(4) Dilli, S.; Garnett, J. L. J. Appl. Polym. Sci. 1967, 11, 859-870.

(5) Moore, P. W. Rev. Pure Appl. Chem. 1970, 139-158.

(6) Arthur, J. C., Jr. Adv. Macromol. Chem. 1970, 2, 1-87.

(7) Dworjanyn, P. A.; Garnett, J. L.; Khan, M. A.; Xu, M.; Qian, M. P.; Nho, Y. C. Radiat. Phys. Chem. 1993, 42, 31-40.

(8) Bhattacharyya, S. N.; Maldas, D. Prog. Polym. Sci. 1984, 10, 171270.

(9) Georges, M. K.; Veregin, R. P. N.; Kazmaier, P. M.; Hamer, G. K. Macromolecules 1993, 26, 2987-2988.

(10) Hawker, C. J. J. Am. Chem. Soc. 1994, 116, 11185-11186.
(11) Solomon, D. H. J. Polym. Sci., Part A: Polym. Chem. 2005, 43, 57485764.

(12) Hawker, C. J.; Bosman, A. W.; Harth, E. Chem. Rev. 2001, 101, 36613688.

(13) Matyjaszewski, K.; Xia, J. Chem. Rev. 2001, 101, 2921-2990.

(14) Coessens, V.; Pintauer, T.; Matyjaszewski, K. Prog. Polym. Sci. 2001, $26,337-377$.

(15) Perrier, S.; Takolpuckdee, P. J. Polym. Sci., Part A: Polym. Chem. 2005, 43, 5347-5393.

(16) Moad, G.; Rizzardo, E.; Thang, S. H. Aust. J. Chem. 2005, 58, 379410.

(17) Moad, G.; Rizzardo, E.; Thang, S. H. Aust. J. Chem. 2006, 59, 669692.

(18) Favier, A.; Charreyre, M.-T. Macromol. Rapid Commun. 2006, 27, 653-692.

(19) Barner, L.; Davis, T. P.; Stenzel, M. H.; Barner-Kowollik, C. Macromol. Rapid Commun. 2007, 28, 539-559.

(20) Daly, W. H.; Evenson, T. S.; Iacono, S. T.; Walker, Jones, R. Macromol. Symp. 2001, 174, 155-163.

(21) Lee, S. B.; Koepsel, R. R.; Morley, S. W.; Matyjaszewski, K.; Sun, Y.; Russell, A. J. Biomacromolecules 2004, 5, 877-882.

(22) Carlmark, A.; Malmström, E. J. Am. Chem. Soc. 2002, 124, 900901.

(23) Carlmark, A.; Malmström, E. Biomacromolecules 2003, 4, 17401745.

(24) Zhou, Q.; Greffe, L.; Baumann, M. J.; Malmström, E. Macromolecules 2005, 38, 3547-3549.

(25) Perrier, S.; Takolpuckdee, P.; Westwood, J.; Lewis, D. M. Macromolecules 2004, 37, 2709-2717.

(26) Takolpuckdee, P.; Westwood, J.; Lewis, D. M.; Perrier, S. Macromol. Symp. 2004, 37, 2709-2717.

(27) Takolpuckdee, P. Aust. J. Chem. 2005, 58, 66.

(28) Roy, D.; Guthrie, J. T.; Perrier, S. Macromolecules 2005, 38, $10363-$ 10372.

(29) Quinn, J. F.; Davis, T. P.; Rizzardo, E. Chem. Commun. 2001, 10441045.

(30) Barner-Kowollik, C. Aust. J. Chem. 2001, 54, 343.

(31) Quinn, J. F.; Barner, L.; Rizzardo, E.; Davis, T. P. J. Polym. Sci. Part A: Polym. Chem. 2002, 40, 19-25.

(32) Barner, L.; Quinn, J. F.; Barner-Kowollik, C.; Vana, P.; Davis, T. P. Eur. Polym. J. 2003, 39, 449-459.

(33) Millard, P.; Barner, L.; Stenzel, M. H.; Davis, T. P.; Barner-Kowollik, C.; Müller, A. H. E. Macromol. Rapid Commun. 2006, 27, 821-828.

(34) Barner, L.; Zwaneveld, N.; Perera, S.; Pham, Y.; Davis, T. P. J. Polym. Sci., Part A: Polym. Chem. 2002, 40, 4180-4192.

(35) Barner, L.; Perera, S.; Sandanayake, S.; Davis, T. P. J. Polym. Sci., Part A: Polym. Chem. 2006, 44, 857-864.

(36) Barner, L. Aust. J. Chem. 2003, 56, 1091.

(37) Kiani, K.; Hill, D. J. T.; Rasoul, F.; Whittaker, M.; Rintoul, L. J. Polym. Sci., Part A: Polym. Chem. 2007, 45, 1074-1083.

(38) Barner-Kowollik, C.; Quinn, J. F.; Nguyen, T. L. U.; Heuts, J. P. A.; Davis, T. P. Macromolecules 2001, 34, 7849-7857.

(39) Zeronian, S. H. In Cellulose Chemistry and its Application; Nevell, T. P., Zeronian, S. H., Eds.; Ellis Horwood Limited: New York, 1985 pp 168-170.

(40) Chapiro, A. Radiation Chemistry of Polymeric Systems; Interscience: New York, 1962.

(41) Florin, R. E.; Wall, L. A. J. Polym. Sci. Part A: Gen. Pap. 1963, 1, $1163-1173$

(42) Guthrie, J. T.; Huglin, M. B.; Phillips, G. O. J. Appl. Polym. Sci. 1972, 16, 1017-1037.

(43) Lin-Vien, D.; Colthup, N. B.; Fateley, W. G.; Grasselli, J. G. The Handbook of Infrared and Raman Characteristic Frequencies of Organic Molecules; Academic Press: London, UK 1991.

(44) Note: If one plots the increase of the styrene peak relative to the (constant and nonchanging) cellulose peak, a linear relationship with respect to the percentage weight gain is obtained.

(45) Song, Y.; Massera, C.; van Albada, G. A.; Manotti Lanfredi, A. M.; Reedijk, J. J. Mol. Struct. 2005, 734, 83-88.

(46) Serita, M.; Tamaoki, M.; Itoh, K. J. Phys. Chem. 1988, 92, 17471751.

(47) Román-Aguirre, M.; Márquez-Lucero, A.; Zaragoza-Contreras, E. A. Carbohydr. Polym. 2004, 55, 201-210.

(48) Plamper, F. A.; Becker, H.; Lanzendörfer, M.; Patel, M.; Wittemann, A.; Ballauff, M.; Müller, A. H. E. Macromol. Chem. Phys. 2005, 206, $1813-1825$

(49) Miwa, Y.; Yamamoto, K.; Sakaguchi, M.; Shimada, S. Macromolecules 2001, 34, 2089-2094.

(50) Stehling, U. M.; Malmström, E. E.; Waymouth, R. M.; Hawker, C. J. Macromolecules 1998, 31, 4396-4398. 